\title{
ARTIGOS
}

\section{Distribuição espacial de Phytophthora nicotianae e reação de cultivares de cebola ao fungo*}

\author{
Fernandes Antonio de Almeida ${ }^{1}$; Modesto Barreto ${ }^{2}$; José Carlos Barbosa ${ }^{3}$; Frank Magno da Costa ${ }^{2}$.
}

${ }^{1}$ UFPI- Campus Universitário, BR 135, km 3, Bom Jesus-PI, CEP.64.900-000.; ${ }^{2}$ FCAV/UNESP, Departamento de Fitossanidade, CEP. 14.884900, Jaboticabal, SP, ${ }^{3} \mathrm{FCAV} / \mathrm{UNESP}$, Departamento de Ciência Exatas, Jaboticabal, SP. * Parte da Tese de Doutorado do primeiro autor.

Autor para correnpondência: Fernandes Antonio de Almeida (fernandes@ufpi.edu.br)

Data de chegada: 12/12/2007. Aceito para publicação em: 18/01/2011.

\section{RESUMO}

Almeida, F.A.; Barreto, M.; Barbosa, J.C.; Costa, F.M.. Distribuição espacial de Phytophthora nicotianae e reação de cultivares de cebola ao fungo. Summa Phytopathologica, v.37, n.1, p.13-17, 2011.

A cultura da cebola vem se mostrando altamente suscetível ao ataque de Phytophthora nicotianae, com danos econômicos e alto custo de produção pelo uso excessivo de produtos químicos. O presente trabalho teve como objetivo avaliar a dependência espacial do patógeno por meio da Geoestatística e em seguida, testar a resistência de cultivares de cebola sob sistema convencional de cultivo ao fungo. Os experimentos foram conduzidos no campus da FCAV-UNESP. Para detectar a presença do fungo nas amostras de solo, foram coletadas e processadas em laboratório onde, discos de folhas de limão Siciliano (Citrus limonum) foram utilizados como "iscas" na suspensão do solo para contagem desses discos infectados. Logo após, na mesma unidade experimental, avaliou-se treze cultivares (Dom Victor, BZ 21; Princesa, Taiko, Óptima, BZ 50, Mercedes, Sunset, Duquesa, Gobi, Sirius, Colina e Superex) de cebola, num experimento com delineamento em blocos casualizados com quatro repetições. Foram feitas avaliações semanais, do transplantio até a colheita. Pelo modelo de semivariograma isotrópico esférico ajustado aos dados, os resultados demonstraram não haver dependência espacial, revelando que a área apresentava uma distribuição agregada do patógeno. Com o mapeamento pelo método de Krigagem ordinário em blocos, verificou-se maior incidência do fungo, entre os três primeiros canteiros localizados na baixadas, com uma redução gradual para o restante que apresentou menor declividade na área. Dentre as cultivares avaliadas quanto à resistência ao fungo - Mercedes, Princesa e Duquesa são altamente suscetíveis, e as demais, demonstraram baixa suscetibilidade ao patógeno nessa primeira avaliação de campo.

Palavras-chave adicionais: Allium cepa, geoestatística, patógeno.

\section{ABSTRACT}

Gasparotto, F.; Vida, J.B.; Tessmann, D.J.; Alves. T.C.A.. Space distribution of Phytophthora nicotianae and reaction to cultivars from onion to the fungal. Summa Phytopathologica, v.37, n.1, p.13-17, 2011.

Onion culture has demonstrated to be highly susceptible to Phytophthora nicotianae with economic damages and high crop costs due to the excessive use of chemical products. The present work has as objective to evaluate the spatial dependence of pathogen by Geostatistic and after that, to test the resistance of onion cultivars to this disease under conventional crop. The experiments were conducted at FCAV/UNESP. Soil samples were collected and processed at the laboratory in relation to pathogen, presence through the count of disks of Sicilian lemon infected of the solution of the soil. Immediately after that, at the same experimental unit, thirteen onion cultivars (Dom Victor, BZ 21; Princesa, Taiko, Óptima, BZ 50, Mercedes, Sunset, Duquesa, Gobi,
Sirius, Colina e Superex) were analysed in a randomized blocks design with four repetitions. Weekly evaluations were effectuated, from transplanting to harvest. By spherical isotropic semivariogram model, results demonstrated no spatial dependence, revealing that the area presented uniform distribution of the pathogen. With the mapping incidence by Krigage method in blocks, it was verified higher incidence of fungi between the first three patches of lower place, being sequenced reduced with area declivity. No cultivar evaluated presented resistance to the pathogen. It's detached that - Mercedes, Princesa and Duquesa cultivars are highly susceptible, and the others demonstrated low susceptibility to the pathogen in that first field evaluation.

Palavras-chave adicionais: Allium cepa, geostatistics, pathogen.

A cebola (Allium cepa L.), dentre as espécies cultivadas pertencentes ao gênero Allium é a mais importante tanto em volume de consumo quanto em valor econômico. No Brasil, a produção de cebolas concentra-se praticamente em todas as regiões, atividade essas exercida na grande maioria por pequenos e médios produtores, contribuindo diretamente na geração de emprego e na fixação do homem no campo (3). Vários fatores contribuem para baixa produtividade da cultura, entre estes, destaque para as doenças causadas por diversos patógenos. Porém, entre os anos de 2002 a 2004, os principais pólos produtores no Estado de São Paulo (Monte Alto, Piedade e São José 
Rio Pardo), contabilizaram prejuízos em alguns casos acima de $90 \%$, pela incidência de uma nova doença na cultura, causada por Phytophthora nicotianae Breda de Haan (1896) (sin. P. parasitica Dastur (1913)), que até então não relatada nos campos de produção desta região (Barreto \& Scaloppi (1)). A doença é observada em pré e pós-emergência, porém sob condições favoráveis, como o plantio em áreas de ocorrência anteriores, solos encharcados, elevada temperatura e umidade relativa, as plantas são facilmente destruídas ao ataque dos patógenos (1). Esse processo se caracteriza por queima foliar, muitas vezes tem seu início pela base das folhas, que com seu desenvolvimento, se direciona para o centro e a ponta da mesma, e logo ocorre estrangulamento e morte da folha (Reis et al. (18)). Os sintomas mais comuns ocorrem logo após a germinação, com encharcamento e necrose dos tecidos na região da base das plântulas, provocando afinamento, tombamento e posterior apodrecimento de bulbos Barreto \& Scaloppi (1). Sintomas semelhantes foram descritos na cultura do maracujá (Passiflora edulis f. flavicarpa Deg.) em viveiros de mudas ocasionando "damping-off" (Cole et al. (7); Gonzalez et al. (12)). Em estudos realizados por (Fischer et al. (10)), observaram a interação entre Phytophthora nicotianae e Nectria haematococca, uma vez que foi confirmado um grande número de mortalidade de plantas de maracujazeiro no município de Vera Cruz-SP. O conhecimento no desenvolvimento da doença no tempo e no espaço permite conhece de forma detalhada sua interação com o hospedeiro, além de contribuir com o manejo adequado da doença garante aumento da produtividade (Talamini (22); Bergamin Filho et al. (2)). Porém, alguns métodos estatísticos clássicos não parecem ser apropriados para caracterizar padrões espaciais de doenças em plantas, por não considerar a dependência espacial (Bergamin Filho et al. (2); Campbell \& Madden (4)). A teoria da variável regionalizada é considerada a base dos fundamentos da geoestatística, e vem demonstrando resultados claros em todas as áreas aplicadas, que consideram a distância entre amostras necessárias para quantificar e representar a dependência espacial com estimação mais precisa Clark (6). A variação espacial em um campo pode influenciar todos os fatores de produção como a fertilidade ou atividade microbiana. A geoestatística vem sendo empregada para melhor compreender o padrão espaço-temporal, na tentativa de gerar respostas mais condizente sobre aspectos epidemiológicos de doenças nas plantas, devido ao padrão agregado do inóculo e da doença (Chellemi et al. (5) \& Larkin et al. (14)). Alguns Patógenos como espécies do gênero Phytophthora, têm demonstrado características de infestação em agregação, o que pode caracterizar dependência espacial, e a necessidade de utilização de um novo modelo para análise que melhor demonstre esse comportamento específico que ocorre entre alguns microrganismos (Chellemi et al. (5)). O presente trabalho teve como objetivo avaliar a dependência espacial do patógenos em canteiros por meio da Geoestatística e em seguida, testar a resistência de cultivares de cebola sob sistema convencional de cultivo a esta doença na mesma área.

\section{MATERIAL E MÉTODOS}

Foram realizados dois ensaios no Departamento de Fitossanidade, FCAV-UNESP, Campus de Jaboticabal, com as coordenadas geográficas: $21^{\circ} 15^{\prime} \mathrm{S}$ de latitude; $48^{\circ} 18^{\prime} \mathrm{W}$ de longitude e com $595 \mathrm{~m}$ de altitude. O clima que predomina na região é do tipo temperado mesotérmico, com temperatura média de $22^{\circ} \mathrm{C}$, com inverno seco e verão chuvoso, com precipitação média de $1.424,6 \mathrm{~mm}$ anuais (19). O solo da unidade experimental está assentado na classe Latossolo Vermelho-Escuro (8).

\section{Avaliação do patógeno nos canteiros}

Na unidade experimental foram construídos sete canteiros no ano de 2002, com propósito de manter constantemente um campo de inoculo para P. nicotianae, agente etiológico responsável por grandes perdas em áreas de cebola em um dos principais pólo produtor do Estado de São Paulo (Monte Alto). Para avaliação da distribuição espacial do fungo na área, realizou-se um estudo no período compreendido entre os meses de dezembro de 2005 a maio de 2006. Foram realizados coletas de solo nos sete canteiros existentes na área, em pontos distintos, e confeccionado uma malha com dimensões $2,0 \mathrm{x}$ $1,70 \mathrm{~m}$, totalizando 98 unidades amostrais, para uma área de $335,5 \mathrm{~m}^{2}$. De cada ponto amostrado, foram coletados aproximadamente $200 \mathrm{~g}$ de solo, com auxílio de enxadão, a uma profundidade de até $10 \mathrm{~cm}$. Ao final da coleta, as amostras foram devidamente acondicionadas em sacos plásticos, identificadas, transportadas e analisadas no laboratório de Fitopatologia da FCAV/UNESP, para avaliar a população de $P$. nicotianae do solo. Foi utilizada a metodologia adaptada e descrita por Matheron \& Matejka (15), que consistiu da distribuição do solo coletado, em recipientes com capacidade volumétrica para $1000 \mathrm{~mL}$, acrescentando ao mesmo tempo $400 \mathrm{~mL}$ de água para facilitar um completo destorroamento. Em seguida, foram distribuídos nos recipientes contendo a solução do solo, 30 discos de folha de limão Siciliano (Citrus limonum) de $3 \mathrm{~mm}$ de diâmetro que permaneceram flutuando, como "iscas", por $72 \mathrm{~h}$ sob luz fluorescente branca e temperatura ambiente de aproximadamente $28^{\circ} \mathrm{C}$. Ao final do período de incubação, todos os discos expostos na solução do solo, foram avaliados anotando-se o número de disco que havia sido colonizado pelo fungo em uma planilha do Excel com as suas respectivas coordenadas $(\mathrm{x}, \mathrm{y})$, analisando-se sob microscópio óptico, com as objetivas de alcance intermediário entre 10x e 40x de aumento. Os resultados da quantificação, foram empregados na determinação da existência ou não da dependência espacial do fungo, por meio de semivariograma, através do programa GS+ (Robertson (20)). Na elaboração de mapa de distribuição espacial das variáveis foi utilizado o programa Surfer (Golden Software Inc. (11)).

Suscetibilidade de cultivares de cebola a Phytophthora nicotianae.

Ao final do mapeamento do fungo nos canteiros, o segundo ensaio teve seu início em junho 2006, com o transplantio das 13 cultivares de cebola para avaliação de resistência ao patógeno. Foi realizada a semeadura da cebola em bandejas de Poliestireno expandido com 288 cavidades, preenchida com substrato comercial (Plantmax). O transplantio das mudas foi realizado 35 dias após a semeadura para os canteiros. O sistema de irrigação empregado para o ensaio foi por gotejamento, com disponibilização de água sempre na capacidade de campo. A adubação foi realizada aos 30 e 50 dias após o transplantio, em cobertura, aplicando-se a mistura de N-P-K na formulação 10-10$10\left(70 \mathrm{~g} \mathrm{~m}^{-2}\right)$ conforme recomendação da análise. Para o controle preventivo de pragas foram efetuadas 2 pulverizações com Methamidophos (TAMARON BR) com $30 \mathrm{~mL} / 20$ litro de água. $\mathrm{O}$ delineamento experimental empregado foi de blocos casualizados com quatro repetições, onde cada parcela consistiu de quatro fileiras de plantas com $2 \mathrm{~m}$ de comprimento e $1 \mathrm{~m}$ de largura (unidade experimental de $2 \mathrm{~m}^{2}$ ), contendo 80 plantas por parcela, totalizando $104 \mathrm{~m}^{2}$ de área total. Os tratamentos constituíram-se de treze cultivares de cebola (Dom Victor, BZ 21; Princesa, Taiko, Óptima, BZ 50, Mercedes, 
Sunset, Duquesa, Gobi, Sirius, Colina e Superex). As avaliações da incidência da doença foram semanais, do transplantio até a colheita, por meio de contagem direta de plantas mortas. No final foi totalizado o número de plantas mortas em cada mês e o número total. Os dados foram submetidos à análise de variância pelo teste $\mathrm{F}$ e teste de Scott Knott para comparação de média a $1 \%$ de significância.

\section{RESULTADOS E DISCUSSÃO}

\section{Avaliação do patógeno com Geoestatística}

Nas avaliações realizadas através da contagem de discos infectados, sob a forma de "iscas" para quantificação do fungo em amostra de solo por Phytophthora nicotianae em canteiros, pode se perceber claramente que não houve dependência espacial do fungo ao longo de toda a área estudada. De acordo com Sinegani et al. (21), essa situação caracteriza o modelo denominado efeito pepita puro, o que demonstra não ter havido correlação espacial entre as amostras avaliadas nas distâncias empregadas. Do ponto de vista biológico, caracterizou-se com um alto índice de infestação do fungo em toda área amostrada, uma vez que a área experimental foi inoculada em anos anteriores com o mesmo fungo para realização de outros trabalhos. Assim sendo, é possível entender esse resultado por se tratar de um patógeno que apresenta alta capacidade de se manifestar em grande número de hospedeiros (9). Para tanto, se fez necessário a modelagem através do semivariograma, que vem possibilitar estimar por meio de interpolação dos valores da variável para locais não amostrados gerando mapa de isolinhas com maior precisão, conforme explica Queiroz et al. (17). Os resultados correspondentes aos valores no mapa, representados nos canteiros (Figura 2), demonstram que nos sete canteiros estudados, todos apresentavam colonização dos discos pelo fungo com valores igual ou superior a $40 \%$ quantificados através da suspensão do solo. Analisando de forma isolada todos os canteiros empregados dentro da área, é possível observar valores entre 45 e $80 \%$ de atividade microbiana nos quatro canteiros da grade na parte inferior na área experimental (X: 3-
$23 \mathrm{~m}$ e Y: 2,55- 6,6 m) e, os menores valores na parte superior do mapa (Figura 2). Para esses resultados, é possível que tenha havido interferência de aptidão pelo hospedeiro (cebola), que se encontrava cultivado nesses canteiros da área experimental a aproximadamente trinta dias antes do estudo o que não aconteceu para os demais canteiros. Como se trata de um agente do tipo Oomiceto, com diversas estruturas vegetativas e reprodutivas, entre esses, zoósporos biflagelados, consideradas as principais estruturas infectivas do fungo (Hickman (13); Matheron \& Matejka (16)), provavelmente, esse deslocamento diferenciado entre os canteiros, tenha sido ocasionado pelo exsudato da cultura promovendo maior infecção. Outra hipótese, desses valores de colonização acentuados para alguns canteiros, pode ter sido favorecida diretamente pelo acúmulo de água empregada na irrigação. Em geral, a confecção do mapa de isolinhas, proporcionou uma localização entre os canteiros com incidência do fungo diferenciada. Dessa maneira, é possível direcionar diversas medidas de controle com maior eficiência. Mesmo não tendo sido demonstrado nenhuma dependência espacial do fungo para essas condições, os resultados serviram para dar continuidade ao trabalho no teste de 13 cultivares de cebola, na tentativa de serem apontadas as melhores que respondessem com resistência ao fungo sem perda de produção.

\section{Avaliação das cultivares de cebola}

Após ter sido feito o estudo da distribuição espacial, pode ser observado ao final do ensaio, que nos dois primeiro meses (julho e agosto) de avaliações (Tabela 1) não houve diferença significativa entre as cultivares testadas, esse fato pode ser atribuído às baixas temperaturas neste período das avaliações, que ficaram em média em $20^{\circ} \mathrm{C}$, quando se sabe que o patógeno tem preferência por temperaturas acima de $29^{\circ} \mathrm{C}$ Barreto \& Scaloppi (1). A mortalidade de plantas em todos os canteiros confirma a distribuição espacial uniforme do fungo ao longo de toda área já estudada por meio da Geoestatística. Ao contrário dos meses subseqüentes (setembro e outubro) os resultados foram significativos (Tabela 1) conforme análise de variância. Para o terceiro mês, correspondente a setembro, os tratamentos com as

Semiv ariograma

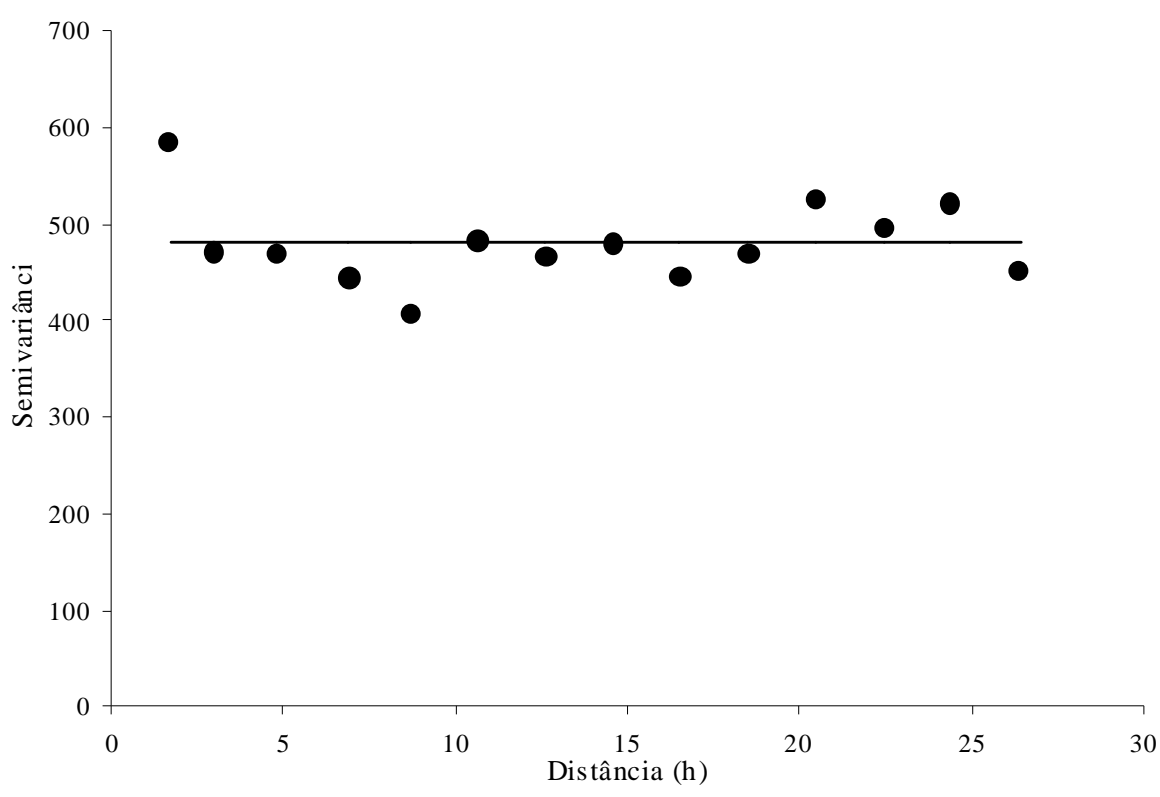

Figura 1. Semivariograma experimental omnidirecional do modelo para o número de discos infectados por zoósporos de Phytophthora nicotianae em canteiros. Jaboticabal, FCAV-UNESP, 2006. 


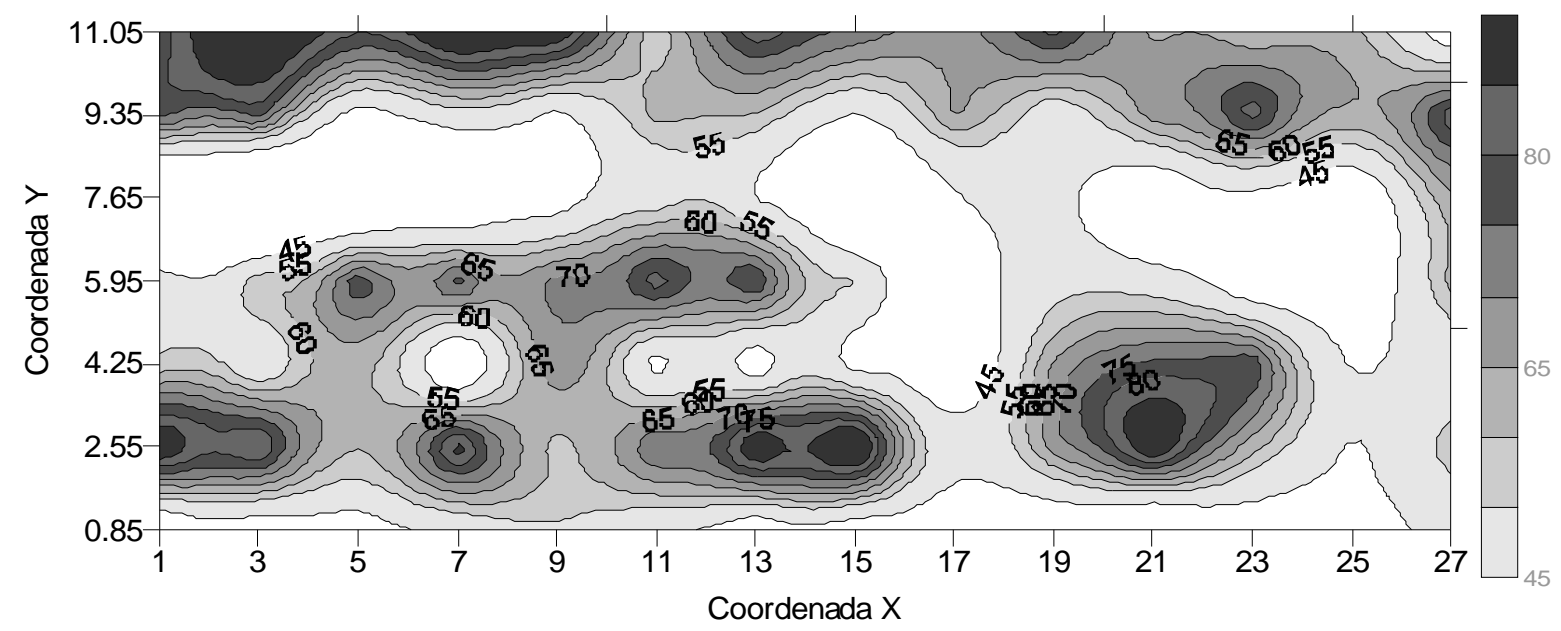

Figura 2. Mapa de isolinhas representando a distribuição espacial da incidência do fungo nos canteiros na área. Jaboticabal, FCAV-UNESP, 2006.

Tabela 1. Número médio/planta de cebolas mortas por Phytophthora nicotianae, avaliadas em canteiros. Jaboticabal, SP, FCAV-UNESP, 2006.

\begin{tabular}{llllll}
\hline \multirow{2}{*}{ Tratamentos } & \multicolumn{5}{c}{ Avaliações } \\
& \multicolumn{5}{c}{ Plantas mortas por Phytophthora nicotianae } \\
\cline { 2 - 6 } & Julho & Agosto & Setembro & Outubro & Total \\
\hline \multirow{2}{*}{ Mercedes } & $2,0 \mathrm{a}$ & $1,8 \mathrm{a}$ & $6,0 \mathrm{a}$ & $3,1 \mathrm{a}$ & $7,2 \mathrm{a}$ \\
Princesa & $2,1 \mathrm{a}$ & $1,9 \mathrm{a}$ & $5,9 \mathrm{a}$ & $3,3 \mathrm{a}$ & $7,2 \mathrm{a}$ \\
D. Victor & $1,5 \mathrm{a}$ & $1,7 \mathrm{a}$ & $1,5 \mathrm{c}$ & $1,8 \mathrm{~b}$ & $2,8 \mathrm{~b}$ \\
Colina & $1,4 \mathrm{a}$ & $1,5 \mathrm{a}$ & $1,1 \mathrm{c}$ & $1,6 \mathrm{~b}$ & $2,6 \mathrm{~b}$ \\
Óptima & $1,5 \mathrm{a}$ & $1,9 \mathrm{a}$ & $2,3 \mathrm{~b}$ & $1,8 \mathrm{~b}$ & $3,4 \mathrm{~b}$ \\
Taiko & $1,5 \mathrm{a}$ & $1,5 \mathrm{a}$ & $2,1 \mathrm{~b}$ & $1,6 \mathrm{~b}$ & $3,0 \mathrm{~b}$ \\
BZ21 & $1,6 \mathrm{a}$ & $1,5 \mathrm{a}$ & $1,3 \mathrm{c}$ & $1,4 \mathrm{~b}$ & $2,4 \mathrm{~b}$ \\
BZ50 & $1,5 \mathrm{a}$ & $1,5 \mathrm{a}$ & $1,4 \mathrm{c}$ & $1,3 \mathrm{~b}$ & $2,2 \mathrm{~b}$ \\
Superex & $1,6 \mathrm{a}$ & $1,5 \mathrm{a}$ & $1,4 \mathrm{c}$ & $2,1 \mathrm{~b}$ & $3,0 \mathrm{~b}$ \\
Sirius & $1,7 \mathrm{a}$ & $1,5 \mathrm{a}$ & $2,7 \mathrm{~b}$ & $1,5 \mathrm{~b}$ & $3,5 \mathrm{~b}$ \\
Gobi & $1,6 \mathrm{a}$ & $1,5 \mathrm{a}$ & $1,7 \mathrm{~b}$ & $1,9 \mathrm{~b}$ & $3,0 \mathrm{~b}$ \\
Duquesa & $2,3 \mathrm{a}$ & $1,7 \mathrm{a}$ & $2,8 \mathrm{~b}$ & $2,7 \mathrm{a}$ & $4,7 \mathrm{~b}$ \\
Sinset & $2,0 \mathrm{a}$ & $1,7 \mathrm{a}$ & $1,3 \mathrm{c}$ & $2,1 \mathrm{~b}$ & $3,3 \mathrm{~b}$ \\
\hline F & $0,88{ }^{\mathrm{ns}}$ & $0,68^{\mathrm{n}}$ & $19,54^{* *}$ & 3,88 & 11,48 \\
\hline CV $(\%)$ & 39,3 & 26,2 & 31,1 & 32,4 & 26,56 \\
\hline
\end{tabular}

'Médias seguidas pela mesma letra nas colunas não diferem, entre si, pelo teste de Scott Knott a $1 \%$ de probabilidade. Dados transformados em $\sqrt{x}+1$.

cultivares Mercedes e Princesa, diferiram estatisticamente dos demais, apresentando percentagem de mortalidade de plantas entre $45 \%$ e $43,5 \%$ respectivamente. Essa baixa resistência ao fungo por essas cultivares mencionadas, confirma o que já tinha sido observado em campo de produtores da região, através de consultas realizadas no laboratório de Fitopatologia da FCAV-UNESP, entre os anos de 2002 a 2004, período de maior incidência do fungo na região. Para o mês de outubro, apesar de diferenças significativas, o maior número de plantas mortas continuou sendo para as cultivares Mercedes; Princesa e Duquesa com valores bem abaixo visto no mês anterior (12\%; 13,6\% e $9,1 \%$ ), respectivamente. Os resultados entre as cultivares demonstraram ter alguma resistência ao fungo ao longo do ensaio, no entanto, percebeu-se diferença entre essa suscetibilidade quando avaliado o número total de plantas mortas. As cultivares Mercedes, Princesa tiveram índice de mortalidade de plantas total superior a $64 \%$, demonstrando serem altamente suscetíveis ao patógeno, seguido por Duquesa com 27,6\%, que demonstrou suscetibilidade intermediária entre elas. As demais cultivares, com destaque para BZ50, apresentou a menor percentagem de plantas mortas total com $(6,1 \%)$, caracterizando baixa suscetibilidade, porém não deferindo das demais cultivares (D. Victor, Colina, Óptima, Taiko, BZ21, Superex, Sirius, Gobi, Sinset) estatisticamente. Portanto, se faz necessário à utilização de novos testes com as cultivares que apresentaram menor percentagem de plantas mortas, assim como também, com outras em períodos e localidades distintas. Aliando a utilização de cultivares, o controle da doença deve enfocar também técnicas de manejo mais apropriada para o solo, água, adubação, período de plantio, além do uso de defensivos adequados.

\section{AGRADECIMENTOS}

Á CAPES pela concessão da bolsa de Doutorado a F. A. de Almeida, assim como também, a empresa AGROMONTES, pelo fornecimento de material vegetal durante todo o ensaio.

\section{REFERÊNCIAS BIBLIOGRÁFICAS}

1. Barreto, M.; Scaloppi, E.A.G. Ocorrência de Phytophthora nicotianae na cultura da cebola. Fitopatologia Brasileira, Brasília, v. 29, supl., p. 201-202, 2004. (Resumo).

2. Bergamin Filho, A., Hau, B., Amorim, L., \& Jesus Junior, W.C. Análise espacial de epidemias. In: Vale, F.X.R., Jesus Junior, W.C. \& Zambolim, L. (Eds.) Epidemiologia aplicada ao manejo de doenças de doenças de plantas. Belo Horizonte: Editora Perffil. p. 193-240, 2004.

3. Boeing G. Fatores que afetam a qualidade da cebola na agricultura familiar catarinense. Florianópolis: Instituto CEPA/ SC. P. 80,2002

4. Campbell, C.1. \& Madden, L.V. Introduction to plant disease epidemiology. New York. J. Wiley \& Sons. 1990.

5. Chellemi, D.O., Rohrbach, K.G., Yost, R.S. \& Sonoda, R.M. Analysis of the spatial pattern of plant pathogens on diseased plants 
using geoestatistics. Phytopathology, p. 221-226, 1988.

6. Clark, I. Practical Geostatistics. Essex: Applied Science Publishers, p. 129, 1979;

7. Cole, D.L., Hedges, R. \& Ndowora, T.A wilt of passion fruit (Passiflora edulis f. edulis Sims) caused by Fusarium solani and Phytophthora nicotianae var. nicotianae. Tropical Pest Management, p. 362-366, 1992.

8. Embrapa. Centro Nacional de Pesquisa de Solos (Rio de Janeiro, RJ). Sistema brasileiro de classificação de solos. Brasília: Embrapa-SPI; Rio de Janeiro: Embrapa-CNPS, 1999. 412p.

9. Extento Hawaii. Damping-off of green onion seedlings leaf blight and rot of green onion. Disponível em: http:/ www.extento.hawaii.edu. Acesso em: 20 jun. 2005.

10. Fischer, I.H., Kimati, H. \& Hamagushi, W. Ocorrência de Fusarium solani e Phytophthora nicotianae, causando morte prematura do maracujazeiro em Vera Cruz, SP. Summa Phytopathologica, v. 29, p. 79-79, 2003. (Resumo).

11. Golden Software Inc. (Golden, Estados Unidos). SURFER for Windows: realese 7.0: contouring and 3D surface mapping for scientist's engineers, user's guide. New York, 1999. 619p.

12. Gonzalez, M.S., Suarez, Z. \& Rosales, C. Collar rot and wilt of yellow passion fruit in Venezuela. Plant Disease, p. 103, 2000.

13. HICKMAN, C.J. Biology of Phytophthora zoospores. Phytopatology, St. Paul, v. 60, n. 7. p. 1128-1134, 1970.

14. LARKIN, R.P., GUMPERTZ, M.L. \& RISTAINO, J.B. Geostatistical analysis of Phytophthora epidemic development in commercial bell pepper fields. Phytopathology p.191-203, 1995.

15. MATHERON, M.E.; MATEJKA, J.C. In vitro activity of sodium tetrathiocarbonate on sporulation and growth of six Phytophtho- ra species. Phytopatology, St. Paul, v. 78, n. 9. p. 12348-1237, 1988.

16. MATHERON, M.E; MATEJKA, J.C. Effect of tetrathiocarbanate, metalaxyl and fosetyl-Al on development and control of Phytophthora root rot of citrus. Plant Disease 75, p. 264-268, 1991.

17. QUEIROZ, J.E.; CRUCIANI, D.E.; LIBARDI, P.L. Variabilidade espacial da porosidade drenável de um solo de várzea, no município de Piracicaba, estado de São Paulo. Revista Brasileira de Engenharia Agrícola e ambiental, Campina Grande, v.3 n.2, p. 135-139, 1999.

18. REIS, A.; HENZ, G.P; LOPES, C.A. Sistema de Produção de Cebola (Allium cepa L). Doenças e métodos de controle. EMBRAPA Hortaliças. 2004. Versão Eletrônica. Disponível: http:// www.cnph.embrapa.br/sistprod/cebola/doencas.htm. Acesso em: 20 de jun. 2007.

19. Resenha meteorologica do período 1971-2000. Disponivel: http:/ /www. Fcav.unesp.br/departamento/ciênciasexatas/aract/estação/ resenha 7100htm. Acesso em 05 jul. 2008.

20. ROBERTSON, G.P. GS+ geostatistics for the environmental sciences: GS+ user's guide. Plainwell: Gamma Design Software, 1998. $152 \mathrm{p}$.

21. SINEGANI, A.A.S.; MAHBOOBI, A.A.; NAZARIZADEH, F. The Effect of Agricultural Practices on the Spatial Variability of Arbuscular Mycorrhiza Spores. Faculty of Agriculture, BuAli Sina University, Hamadan - IRAN. Received. P. 12-31, 2004

22. TALAMINI, V. Progresso espacial e temporal da Antracnose a partir de diferentes níveis de inoculo inicial em sementes de feijoeiro. 2003. 110 f. Tese (Doutorado em Fitopatologia) - Universidade Federal de Lavras, Lavras, MG. 